\author{
Mediterranean BioMedical Journals \\ Integrative Journal of Medical Sciences \\ 2020, Volume 7, ID 165 \\ DOI: $\underline{\text { 10.15342/ijms.7.165 }}$
}

CASE REPORT

\title{
Management of Massive Tibial Bone Defect using Unifocal Bone Transport with Ilizarov Apparatus: A Case Study
}

\author{
Ayed A Alshahrani ${ }^{1}$, Mohaned Saeed Argan ${ }^{1}$, Waleed Ali A Alqahtani ${ }^{1}$, Majed Abdullah M Al Hoban ${ }^{1}$, \\ Jaya Shanker Tedla 2 (D), Irshad Ahmed 2 \\ 1 : Department of Orthopedic Surgery, Asir Central Hospital, Abha, Kingdom of Saudi Arabia \\ 2 : Department of Medical Rehabilitation, College of Applied Medical Sciences, King Khalid University, Abha, Kingdom of Saudi Arabia.
}

\begin{abstract}
Introduction: Ilizarov technique is one of the excellent methods used for bony lengthening. The current literature states that the maximum possible amount of tibial lengthening by bifocal transport of an Ilizarov apparatus was $22 \mathrm{~cm}$, while the maximum amount of tibial lengthening by unifocal transport of an Ilizarov apparatus was $14.5 \mathrm{~cm}$.

Case report: 40 years old Saudi teacher was presented with an open fracture at right tibia of type 3B. Second debridement was done and ended up with $21.49 \mathrm{~cm}$ bone loss of middle Tibial segment. Local flap plastic surgery was done to cover the skin defect and the bone transport was done with a rate of $1 \mathrm{~mm} /$ day. The overall healing was excellent, and the patient returned to his preinjury functional activity and rejoined his job as a teacher.

Conclusion: Thus, the current case report is a unique new record of $21.49 \mathrm{~cm}$ of tibial lengthening achieved by Ilizarov apparatus using unifocal transport. This will be a treatment hope for the patients with excessive bone loss.
\end{abstract}

KEYWORDS: Ilizarov technique, tibia, fracture, and lengthening.

Correspondence : Dr. Jaya Shanker Tedla, Assistant Professor, Department of Medical Rehabilitation, College of Applied Medical Sciences, King Khalid University, Abha, Kingdom of Saudi Arabia. Email: jtedla@kku.edu.sa

Copyright $\odot 2020$ Ayed A Alshahrani et al. This is an open access article distributed under the Creative Commons Attribution 4.0 International, which permits unrestricted use, distribution, and reproduction in any medium, provided the original work is properly cited.

\section{INTRODUCTION}

In orthopedic surgery, one of the common methods used to lengthen or reshape the limb bones is the Ilizarov apparatus. This limb spacing method is used to treat infected bones, complex and /or open bone fractures which cannot be treated with other methods. Trauma following an aseptic or septic nonunion open fracture can lead to segmental bone defects. The traditional approaches to deal with bone segmental defects include open bone grafting, autogenous bone grafting, transplantation of allograft bone, posterior lateral bone grafting of the tibia, and fibula protibia procedures. However, all these methods require complicated and sequenced surgical interventions as well as the avoidance of heavy weight-bearing during treatment with incomplete reconstruction. Bone transport and vascularized bone grafts performed with the Ilizarov technique show much better results than other techniques. However, each still has its own disadvantages and advantages. [1]

\section{CASE PRESENTATION}

A 40-year-old male teacher of Saudi Arabia nationality was presented with a right leg crush injury due to a traffic accident with bone loss of the middle third of the right tibia. The patient was initially seen in the local hospital, where debridement and external fixation were performed (Figures 1a, 1b, and 1c), then referred to our hospital as a case of open fracture at the right tibia of type $3 \mathrm{~B}$. 


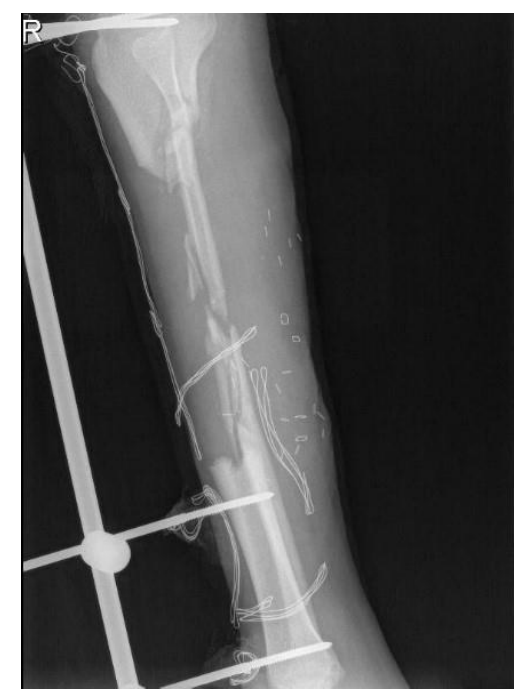

Figure (1a): X-ray showing the entire bone defect of the tibia before the Ilizarov procedure

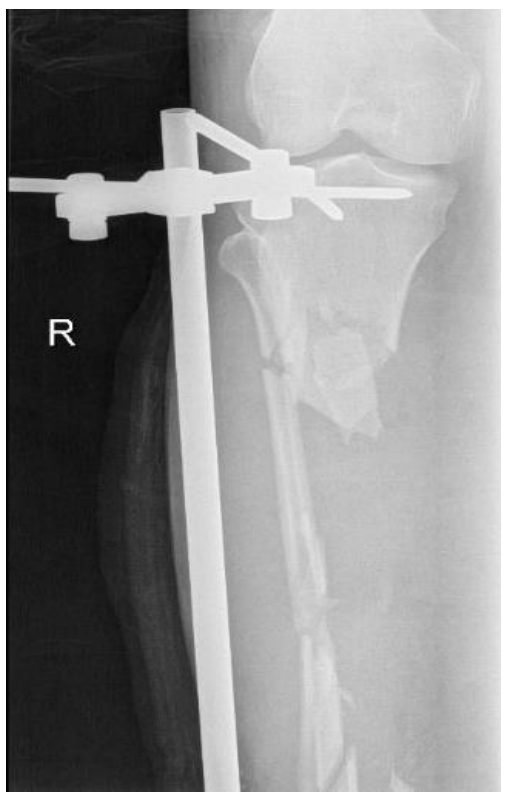

Figure (1b): X-ray showing the upper bone defect of the tibia before the Ilizarov procedure.

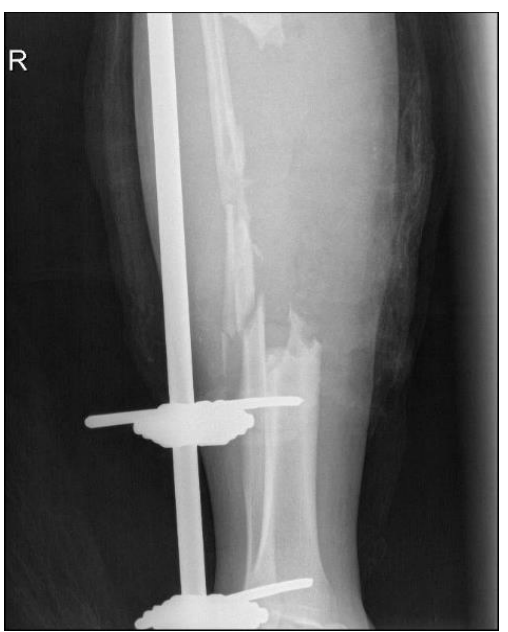

Figure (1c): X-ray showing the lower bone defect of the tibia before the Ilizarov procedure.
The patient was assessed in our hospital and further debridement was performed, ending up with $21.49 \mathrm{~cm}$ of bone loss from the middle tibial segment (Figure 2a).

The plastic surgeon established a local flap to cover the skin defect and the patient was taken for bone transplant surgery with an Ilizarov frame in place aiming to prepare him for retrograde monofocal transport. He was kept on the frame for seven days, then bone transport was performed at a rate of $1 \mathrm{~mm} /$ day (Figure $2 \mathrm{~b}$ ).

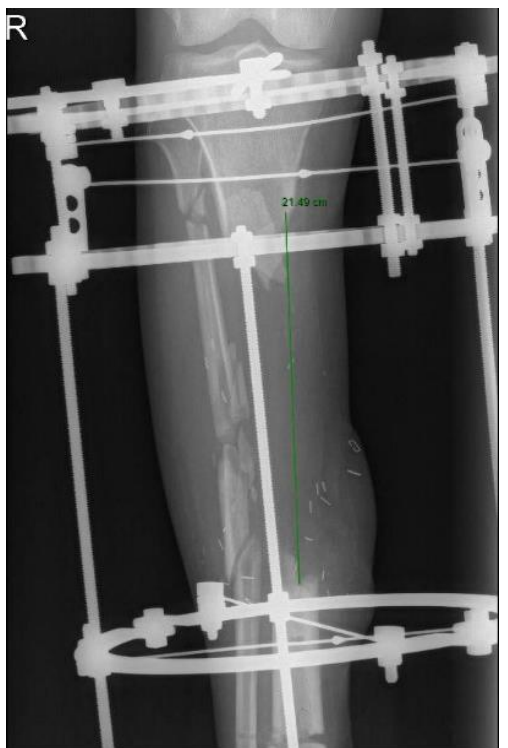

Figure (2a): X-ray showing $21.49 \mathrm{~cm}$ bone deficit on the Ilizarov frame.

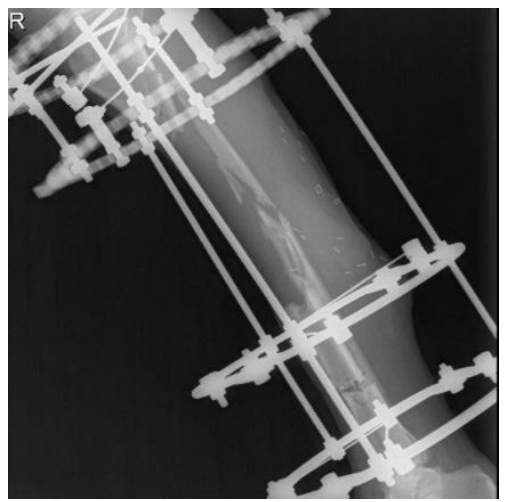

Figure (2b): X-ray showing bone transport on the Ilizarov frame.

During the initial evaluation in physical therapy, the patient complained of severe pain in the movement of the knee and ankle. The visual analog scale pain score was seven of 10 points on knee extension, six of 10 points on knee flexion, eight of 10 points on plantar flexion, and five of 10 points on dorsiflexion. The range of motion was limited in the initial assessment of knee flexion of $90^{\circ}$, Knee extension lag of $30^{\circ}$, ankle dorsiflexion of $10^{\circ}$, and plantar flexion of $15^{\circ}$. Most of the range of movement limitations were due to pain. During his stay in the hospital, the patient underwent physical therapy. His pain was managed by using transcutaneous electrical nerve stimulation and the range of motion was improved by active-assisted and active unassisted exercises. The endrange limitations of knee extension and dorsiflexion were achieved by proprioceptive neuromuscular facilitation with the hold relax technique implemented by the physical therapist. 
Muscle-strengthening exercises were taught to the patient and continued at home until the targeted lengthening was achieved. After achieving the target length of the bone, the patient underwent for docking of the segment by an iliac bone graft. After the bone graft and docking, the patient was kept on the Ilizarov apparatus for six more months for complete healing. After Ilizarov apparatus removal, the patient was kept in a walking cast for two months and instructed to perform full weight-bearing on the right lower limb. The overall healing was very good except for a few incidents of infection, and the patient ultimately showed nearly a full range of motion in both the right knee and right ankle. The patient was followed for three years (Figures $3 \mathrm{a}$ and $3 \mathrm{~b}$ ), during which time, he returned to his preinjury functional activities and rejoined his job as a teacher. The total duration on the Ilizarov apparatus was 26 months and five days and the healing index was 1.32 months per centimeter of bone growth. The characteristics and events of the case are given in Table 1. The patient's written informed consent was obtained for publication of his case study before writing this case report.

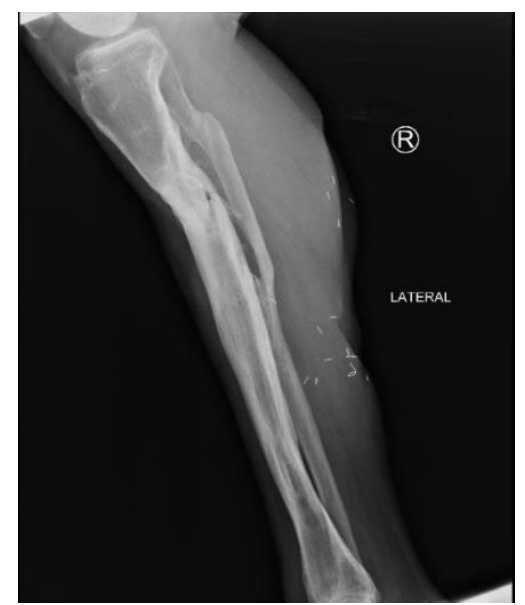

Figure (3a): X-ray two years later showing full consolidation of the docking site and healed status.

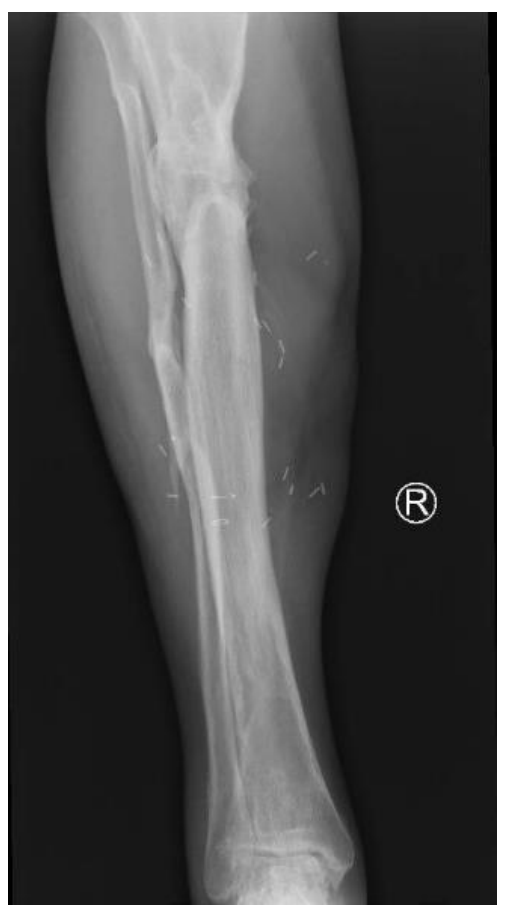

Figure (3b): X-ray two years later showing full consolidation of the docking site and healed status.
Table 1: Characteristics and chronological events of the present case

\begin{tabular}{|c|c|c|}
\hline S. No & Event characteristics & Date \\
\hline 1 & $\begin{array}{l}\text { Initial date of the accident and initial } \\
\text { debridement with external fixation }\end{array}$ & $09-12-2015$ \\
\hline 2 & $\begin{array}{l}\text { Further debridement and local flap } \\
\text { surgery }\end{array}$ & $15-12-2015$ \\
\hline 3 & Ilizarov fixation & 14-01-2016 \\
\hline 4 & Latent period end & 21-01-2016 \\
\hline 5 & $\begin{array}{l}\text { Ilizarov transport by monofocal } \\
\text { method initiated }\end{array}$ & 22-01-2016 \\
\hline 6 & $\begin{array}{l}\text { Transport stopped and iliac bone graft } \\
\text { performed for docking }\end{array}$ & 28-09-2016 \\
\hline 7 & $\begin{array}{l}\text { Ilizarov apparatus removed and kept } \\
\text { on walking cast }\end{array}$ & $18-03-2018$ \\
\hline 8 & End of walking cast usage & $25-05-2018$ \\
\hline 9 & Follow-up after two years & 19-03-2019 \\
\hline
\end{tabular}

\section{DISCUSSION}

The current evidence states that the maximum possible amount of tibial lengthening prompted by bifocal transport of an Ilizarov apparatus is $22 \mathrm{~cm}$, while the maximum amount of tibial lengthening by unifocal transport of an Ilizarov apparatus was $14.5 \mathrm{~cm}$. [2] Thus, the current case report is a unique new record of $21.49 \mathrm{~cm}$ of tibial lengthening achieved by Ilizarov apparatus use using unifocal transport over a duration of two years, two months, and five days.

Bone transport using the Ilizarov technique is clinically considered in reconstructive surgery. External fixators intended to accomplish the surgical objective of handling bone defects using the philosophies of distraction osteogenesis are numerous and variable. [3] Bone transport is a considerable safe technique for managing bone loss in the femur and tibia fractures. The long duration of treatment and the recurrent prescriptions for medications make this method of surgery unfavorable for the socially underprivileged, mentally deficient persons, or those lacking family and community support.

New techniques in the treatment of large segmental bone defects have been documented. Distraction osteogenesis and the induced membrane technique are equally considered novel methods. However, the necessity for suitable autologous bone grafts in the induced membrane technique makes this choice a less suitable choice for this case. [4]

Defect management using the bone transport technique with the Ilizarov apparatus is a clinically significant choice in filling massive bone defects. 2 This is the preferred technique in the case of young and cooperative patients with good family support as this technique requires time and patience to ensure success. Also, the patient's age is of a degree of importance in the alteration of the distraction amount to avoid difficulties such as premature merging or beyond the capacity of ingrowth of the vascular supply. [5] Green et al. previously reviewed 17 cases with segmental skeletal defects treated by Ilizarov intercalary bone transport. On an average, the redeveloped new bone measured $5.14 \mathrm{~cm}$, corresponding to the construction of novel osseous tissue equivalent to $13.7 \%$ of the original length of the bone; further, the meantime for fixation was 9.6 months, counting the 4.8 months to transport the bone fragment through the limb. |[6]

Dendrinos et al. reported on 28 cases with infected nonunion of the tibia managed by the Ilizarov procedure. [7] The average bridged bone defect here was $6 \mathrm{~cm}$, and $64 \%$ of the patients achieved excellent to good functional results. Meanwhile, Al Shahrani et al. reported a level of effectiveness of the Ilizarov technique on a functional consequence in aseptic tibial nonunion patients at 
Kingdom of Saudi Arabia, where the mean bone loss reported was $4.42(2.97) \mathrm{cm}$ and at least $80 \%$ of cases showed improvements in the functional outcomes. [8] In the current case, the amount of bone loss was more than that in both these studies at $21.49 \mathrm{~cm}$, while the functional recovery was full at 26 months.

Paley and Maar treated 19 cases with tibial bone loss caused by osteomyelitis or tibial fractures managed by the Ilizarov bone transport technique and described an average of 2.9 operations per patient, while the average external fixator period was 16 months for an average bone defect of $3.9 \mathrm{~cm}$ and an average transport gap of $10.7 \mathrm{~cm}$. When we compared these outcomes with our case, we required 26 months to address a $21.49-\mathrm{cm}$ bone defect, thus representing a faster rate. Also, the healing index described in their research was 1.7 months $/ \mathrm{cm}$ as compared with 1.32 months/cm in our study. [9]

\section{AUTHORS' CONTRIBUTIONS}

The participation of each author corresponds to the criteria of authorship and contributorship emphasized in the Recommendations for the Conduct, Reporting, Editing, and Publication of Scholarly work in Medical Journals of the International Committee of Medical Journal Editors. Indeed, all the authors have actively participated in the redaction, the revision of the manuscript and provided approval for this final revised version.

\section{ACKNOWLEDGMENT}

We thank Department of Orthopedics, Asir Central Hospital, Abha, Kingdom of Saudi Arabia and Department of Medical Rehabilitation Sciences, College of Applied Medical Sciences, and King Khalid University for the continuous encouragement and support.

\section{REFERENCES}

[1] Spiegelberg B, Parratt T, Dheerendra SK, Khan WS, Jennings R, Marsh DR. Ilizarov principles of deformity correction. Ann R Coll $\begin{array}{lll}\text { Surg } & \text { Engl. } & 2010\end{array}$ DOI:10.1308/003588410X12518836439326

[2] Alkenani NS, Alosfoor MA, Al-Araifi AK, Alnuaim HA. Ilizarov bone transport after massive tibial trauma: Case report. Int J Surg Case Rep. 2016;28:101-6. DOI:10.1016/j.ijscr.2016.08.040

[3] Mora R, Bertani B, Pedrotti L, Tuvo G, Gili S. Compressiondistraction methods. In: Nonunion of the Long Bones: Diagnosis and Treatment with Compression-Distraction Techniques. Springer Milan; 2006. p. 89-117. DOI:10.1007/88-470-0409-8 9

[4] Mauffrey C, Barlow BT, Smith W. Management of segmental bone defects. Vol. 23, Journal of the American Academy of Orthopaedic Surgeons. Lippincott Williams and Wilkins; 2015. p. 143-53. DOI: $10.5435 /$ JAAOS-D-14-00018

[5] Paley D, Kovelman HF, Herzenberg JE. Ilizarov technology. Advances in Operative Orthopaedics. St. Louis, Mosby-Year Book. 1993;1:243-87.

[6] Green SA, Jackson JM, Wall DM, Marinow HA, Ishkanian JA. Management of segmental defects by the Ilizarov intercalary bone

\section{CONCLUSION}

Finally, Cattaneo et al. reported on 28 cases of infected nonunion or segmental bone defects of the tibia, where the extremities healed in all cases. The mean length of the redeveloped bone was $6 \mathrm{~cm}$. The general mean time of treatment using the Ilizarov apparatus was nine months for complete segmental bone loss. [10] In our study, we revealed 26 months of Ilizarov apparatus usage achieved $21.49 \mathrm{~cm}$ bone defect resolution and further revealed the clinical efficacy of using the Ilizarov method for filling in a tibial bone defect, which is concordant with the other studies' findings. We did not perform a functional evaluation using any of the available functional or quality of life scales. In the future, larger samples should be treated, and their functional outcomes measured.

\section{STATEMENT OF ETHICS}

"The authors have no ethical conflicts to disclose."

\section{DISCLOSURE STATEMENT}

"The authors certify that there is no conflict of interest with any financial organization regarding the material discussed in the manuscript"

\section{FUNDING SOURCES}

We sincerely thank the Deanship of Scientific Research, King Khalid University, Abha, Kingdom of Saudi Arabia for funding this research project. transport method. Clinical orthopaedics and related research. 1992 Jul(280):136-42. DOI 10.1097/00003086-199207000-00016

[7] Dendrinos GK, Kontos S, Lyritsis E. Use of the Ilizarov technique for treatment of non-union of the tibia associated with infection. The Journal of bone and joint surgery. American volume. 1995 Jun;77(6):835-46. DOI: 10.2106/00004623-199506000-00004

[8] Al Shahrani AA, Tedla JS, Ahmad I. Effectiveness of ilizarov frame fixation on functional outcome in aseptic tibial non-union cases at Abha, Kingdom of Saudi Arabia: An experimental study. Journal of Taibah University Medical Sciences. 2015 Jun 1;10(2):216-21. DOI: 10.1016/j.jtumed.2014.09.002

[9] Paley D, Maar DC. Ilizarov bone transport treatment for tibial $\begin{array}{llll}\text { defects. J Orthop Trauma. 2000;14(2):76-85. } & \text {. }\end{array}$ DOI:10.1097/00005131-200002000-00002

[10] Cattaneo R, Catagni MA, Johnson EE. The treatment of infected nonunions and segmental defects of the tibia by the methods of Ilizarov. Clinical orthopaedics and related research. $1992 \mathrm{Jul}$; 280:143-52. DOI: 10.1097/00003086-199207000-00017 